\title{
Effect of the Arctic Oscillation on precipitation in the eastern USA during ENSO winters
}

\author{
Dagmar Budikova* \\ Department of Geography-Geology, Illinois State University, Normal, Illinois 61790-4400, USA
}

\begin{abstract}
The El Niño-Southern Oscillation (ENSO) and the Arctic Oscillation (AO), respectively, dominate global and Northern Hemispheric climate variability on interannual timescales. Statistical and composite analyses of historical climate records between 1899 and 2007 reveal a strong influence of the AO on eastern USA winter precipitation and atmospheric circulation over the Pacific/North American (PNA) region during ENSO years. Records of the standardized precipitation index (SPI) and anomalies in the $500 \mathrm{hPa}$ geopotential height field show the AO to exert greatest effect on El Niño-related climate. The presence of a strong northwardly displaced polar front jet and a welldeveloped Bermuda high during months when the $\mathrm{AO}$ is positive promotes the influx of warm and moist air from the western Atlantic into the study area, significantly enhancing winter El Niñorelated precipitation in the southeast USA. Negative phases of the AO that coincide with El Niños deepen the lows over the North Pacific and diminish the influence of the Bermuda high on the eastern USA. This modification enhances the influx of northerly air into the study area, bringing unseasonably dry winters to the Midwest and the Ohio Valley. The presence of the negative phase of the AO returns the wintertime circulation and SPI regimes to near-normal values throughout the study area during La Niña winters, whereas no appreciable effects on La Niña-related circulation and SPI regimes are noted when AO becomes positive. The interaction between ENSO and the AO helps to account for the inter-ENSO variability of climate teleconnections across the PNA region, possibly enhancing our ability to provide better winter climate forecasts across the eastern United States during ENSO episodes.
\end{abstract}

KEY WORDS: Climate variability $\cdot$ ENSO teleconnections · Arctic Oscillation · Precipitation · USA Resale or republication not permitted without written consent of the publisher

\section{INTRODUCTION}

First identified by Lorenz (1951), the Arctic Oscillation (AO) or Northern Hemisphere Annular Mode (NAM) (Limpasuvan \& Hartmann 1999), along with its more localized feature called the North Atlantic Oscillation (NAO) (Wallace \& Gutzler 1981), is now recognized as the major contributor to weather and climate variability of the mid- and high latitudes across the Northern Hemisphere ( $\mathrm{NH}$ ) at intraseasonal to interdecadal timescales. The AO is characterized by a dipole fluctuation in pressure of one sign over the Arctic and the opposite sign in mid-latitudes at around $55^{\circ} \mathrm{N}$, with major centers of action near Greenland and the Azores, and a minor one located over the North Pacific. The state of the AO reflects the strength of the polar vortex in the stratosphere and westerly wind flow north of $45^{\circ}$ in the troposphere such that its positive phase is associated with a strong vortex and westerly winds with opposing conditions dominating during the negative phase (Marshall et al. 2001).

The most prominent AO-related climate effects are observed during the cold season over the eastern USA, the North Atlantic sector, Eurasia, and the polar cap (Higgins et al. 2000, 2007, Marshall et al. 2001). The low (high) index of the AO is typically accompanied by anomalously high (low) pressure over the North Atlantic, warm (cool) conditions throughout the midlatitudes of North America and Eurasia poleward of $40^{\circ} \mathrm{N}$, above (below) normal precipitation over northern Europe and southeastern North America, and reduced (enhanced) precipitation over southern 
Europe and northeast North America (Thompson \& Wallace 1998, Marshall et al. 2001). New et al. (2001) demonstrated that the AO explains approximately 48 and $35 \%$ of the area-averaged winter precipitation variability over land in the latitude bands 60 to $80^{\circ} \mathrm{N}$ and 40 to $60^{\circ} \mathrm{N}$, respectively.

The El Niño-Southern Oscillation (ENSO), a natural phenomenon of the equatorial Pacific, is known as the dominant source of global climate variability on interannual timescales (Wallace \& Gutzler 1981). It reflects the oscillation of the atmosphere-ocean system between the coasts of Ecuador to the east and Papua New Guinea and Australia to the west. The ENSO comprises 2 extreme states, the El Niño (warm phase) and La Niña (cool phase) (Wallace \& Gutzler 1981), that reflect the sea surface temperature (SST) conditions across the central and eastern basin of the equatorial Pacific. ENSO explains about $38 \%$ of the interannual variance on globally averaged land precipitation (New et al. 2001). The relationship between ENSO and winter climate of the Pacific/North American (PNA) region has been well documented (Yarnal \& Leathers 1988, Ropelewski \& Halpert 1989, Leathers et al. 1991, Frauenfeld \& Davis 2000, Higgins et al. 2007). The winter anomalies of the tropical atmosphere and ocean associated with the ENSO disperse the Rossby waves into the $\mathrm{NH}$, often exciting the PNA teleconnection pattern (Wallace \& Gutzler 1981). El Niño winters typically coincide with an enhanced PNA pattern marked by a strong meridional flow of the polar jet over the northern USA that results from the presence of an anomalously deep trough or a strong Aleutian low over the North Pacific Ocean, a strong ridge or well-developed Canadian High over the northwestern sections of the North American continent, and a welldeveloped trough or low pressure system over the southeast USA and the Gulf of Mexico. The path of the polar jet, along with the presence of an active subtropical jet over the southern portions of the USA, produces unseasonably warm and dry winters across western Canada and the northwest USA, dry and cool conditions throughout the Ohio Valley region, and wet conditions across the south during El Niño years. During La Niña winters, the teleconnection responses weakly reflect that of a reverse phase of the PNA with significant dry conditions observed only in the south. Yarnal \& Leathers (1988) stressed that the precise position of the ridge-trough pattern has considerable effect on the resulting regional precipitation totals across the eastern USA, an observation that helps account for the inter-ENSO precipitation variability documented across the region (Hoerling \& Kumar 1997).

Recent literature on teleconnections has focused on documenting the climatic effects of ENSO's interaction with other key modes of climatic variability. Across the
PNA region questions have centered on the modulation of winter climates by distinct states of the Pacific Decadal Oscillation (PDO) (e.g. Zhang et al. 1997, Gershunov \& Barnett 1998, Frauenfeld \& Davis 2002, Budikova 2005), the Atlantic Multidecadal Oscillation (AMO) (e.g. Enfield et al. 2001, McCabe et al. 2004), and the NAO (e.g. Rodo et al. 1997, Huang et al. 1998). Recently, Randel (2004) and Taguchi \& Hartmann (2006) demonstrated that ENSO may influence the NAM in both the stratosphere and the troposphere through an enhancement of planetary Rossby wave activity as the waves propagate into the stratosphere and interact with the polar vortex. The enhanced variations in the vortex intensity then communicate downward to the troposphere (Baldwin \& Durkerton 1999). Bronnimann et al. (2004) argued that the signature of El Niño during the early 1940s closely resembled that of the negative NAM from the surface to the $100 \mathrm{hPa}$ level. Hamilton (1993), and, more recently, Labitzke \& van Loon (1999) claimed that the polar vortex tends to be weaker during El Niño winters and stronger during La Niña winters. Quadrelli \& Wallace (2002) explored the effect of ENSO on the AO, and Li et al. (2006) examined the link between the tropical Pacific SST forcing and the AO. Both studies found El Niño and La Niña to be associated with very distinct structures of the AO, the AO structure being significantly modified by the state of ENSO. New evidence is also emerging regarding the effect of the NAM on the ENSO. Thompson \& Lorenz (2004) revealed a coupling between the NAM and the tropical atmosphere, and, more recently, Nakamura et al. (2006) found a connection between spring NAM and ENSO outbreaks during following winter. Bond \& Harrison (2006) showed that ENSO signatures observed in Alaska's winter weather have varied with the extreme phases of the AO.

The present study aims to build on the current literature by exploring the interaction between the $\mathrm{AO}$ and ENSO, with a focus on understanding the influence of the AO on El Niño- and La Niña-related regional precipitation regimes across the eastern USA as defined by the standardized precipitation index (SPI). It is hypothesized that the state of the atmospheric circulation over the $\mathrm{NH}$ influences the structure of the teleconnection pattern that emanates from the equatorial Pacific during ENSO events over North America, affecting the expected surface SPI regimes across the eastern USA. Specific research questions include the following: How do various phases of the AO affect winter El Niño- and La Niña-related atmospheric circulation regimes across the PNA region? What regions of the eastern USA experience the greatest modifications in El Niño- and La Niña-related SPI regimes due to the $\mathrm{AO}$ ? 


\section{DATA AND METHODS}

Winter is defined in this study by the extended season between December and the following March (DJFM). The utilized methods draw upon several data sources spanning the time period between December 1899 and March 2007. Time series of total monthly precipitation were obtained for 260 climate divisions across the study area from the National Climatic Data Center (Asheville, NC) (NCDC 1994). Guttman \& Quayle (1996) described the construction of these divisions, the computation of data values for each month and climate division on record, the data treatment procedures, and discussed the strength and weaknesses of the dataset. The SPI was computed from the monthly precipitation values using the gamma distribution as described by McKee et al. (1993) to obtain an index value for each winter month based on the entire data record. The SPI monitors the probability of anomalously dry or wet events for each year and represents the number of standard deviations from the mean total precipitation value, allowing for precipitation amounts to be more comparable across various geographic regions.

A time series of the monthly Niño-3.4 SST index (Kaplan et al. 1998) was obtained from the International Research Institute for the 1899 to 2007 period. The index represents a spatial average of SST conditions across the central equatorial Pacific $\left(5^{\circ} \mathrm{N}\right.$ to $5^{\circ} \mathrm{S}$, 90 to $150^{\circ} \mathrm{W}$ ) and monitors the state of the ENSO. It was used to classify the 109 winter seasons into El Niño, La Niña, and ENSO-neutral years. A DJFM period was classified as an El Niño (La Niña) if the 5 mo running mean of the Niño-3.4 index exceeded $0.5^{\circ} \mathrm{C}\left(-0.5^{\circ} \mathrm{C}\right)$ for at least 6 consecutive months during and prior to the season. All remaining years were considered ENSO neutral. The resulting classification of years by ENSO phases is shown in Table 1. A total of $24 \mathrm{La}$ Niña $\left(\mathrm{ENSO}^{-}\right), 26 \mathrm{El}$ Niño $\left(\mathrm{ENSO}^{+}\right)$, and 59 ENSO-neutral $\left(\mathrm{ENSO}^{\mathrm{Neu}}\right.$ ) winters were identified by this method.

The AO index was computed by Thompson \& Wallace (1998) by projecting the AO pattern on $\mathrm{NH}$ sea level pressure. A time series of the monthly index spanning the 1899 to 2001 winter periods was obtained from Colorado State University (CSU). Also obtained were records of the monthly AO time series from the Climate Prediction Center (CPC) for the 1950 to 2007 period. The December through March indices were extracted from each data source. The CPC monthly time series for the period 1950-2001 were used to predict the 2002-2007 winter values for the CSU dataset using simple linear regression (Wilks 1995) to obtain a continuous dataset for the AO between 1900 and 2007. The regression coefficients are shown in Table 2. For
Table 1. El Niño, La Niña, and ENSO-neutral winters as defined by the DJFM season (1899 to 2007) (listed years correspond to the months of January through March)

\begin{tabular}{|c|c|}
\hline Niño $\left(\mathrm{ENSO}^{+}\right)$ & $\begin{array}{l}\text { 1900, 1903, 1905, 1906, 1912, 1914, 1915, } \\
\text { 1919, 1920, 1924, 1926, 1930, 1931, 1941, } \\
1942,1958,1966,1970,1973,1983,1987, \\
1992,1995,1998,2003,2005\end{array}$ \\
\hline a Niña $\left(\mathrm{ENSO}^{-}\right)$ & $\begin{array}{l}\text { 1904, 1909, 1910, 1911, 1917, 1925, 1934, } \\
\text { 1939, 1943, 1945, 1950, 1956, 1965, 1971, } \\
\text { 1974, 1975, 1976, 1985, 1989, 1996, 1999, } \\
2000,2001,2007\end{array}$ \\
\hline $\begin{array}{l}\text { ENSO neutral } \\
\text { ENSO }^{\text {Neu}} \text { ) }\end{array}$ & $\begin{array}{l}\text { 1899, 1901, 1902, 1907, 1908, 1913, 1916, } \\
1918,1921,1922,1923,1927,1928,1929, \\
1932,1933,1935,1936,1937,1938,1940, \\
1944,1946,1947,1948,1949,1951,1952, \\
1953,1954,1955,1957,1959,1960,1961, \\
1962,1963,1964,1967,1968,1969,1972, \\
1977,1978,1979,1980,1981,1982,1984, \\
1986,1988,1990,1991,1993,1994,1997, \\
2002,2004,2006\end{array}$ \\
\hline
\end{tabular}

each month, the extrapolated 1899-2007 CSU dataset contained $108 \mathrm{yr}$ of records for December and $109 \mathrm{yr}$ for January through March. The dataset was used to classify all winter months into positive, negative, and neutral phases of the AO by dividing the distributions into thirds (Table 3) (Wilks 1995). Values that fell within the 33.3rd percentile were classified as AO negative $\left(\mathrm{AO}^{-}\right)$, those that fell above the 66.6th percentile were classified as $\mathrm{AO}$ positive $\left(\mathrm{AO}^{+}\right)$. All remaining years were considered AO neutral $\left(\mathrm{AO}^{\mathrm{Neu}}\right)$.

Time series for each of the 4 winter months were obtained for $500 \mathrm{hPa}$ geopotential heights for the 1949-2007 period to examine the atmospheric circulation regimes associated with the various AO-ENSO combinations. The data were obtained for the $\mathrm{NH}$ from the NCEP/NCAR reanalysis (Kalnay et al. 1996) dataset, gridded to a $2.5^{\circ} \times 2.5^{\circ}$ resolution. Monthly anomalies were computed for each dataset based on the period of record.

ENSO teleconnections vary from one event to the next (Hoerling et al. 1997). Teleconnections observed during El Niño are rarely a mirror image of those observed during La Niña (Montroy et al. 1998). This fact is especially true in remote areas far from the

Table 2. Linear regression coefficients used to estimate the Colorado State University Arctic Oscillation time series between 2002 and 2007

\begin{tabular}{|lccc|}
\hline & Slope & Intercept & $\mathrm{r}^{2}$ \\
\hline December & 1.022 & 0.190 & 0.972 \\
January & 1.030 & 0.473 & 0.980 \\
February & 1.011 & 0.455 & 0.971 \\
March & 1.065 & 0.277 & 0.985 \\
\hline
\end{tabular}


Table 3. Month/year classification of the Arctic Oscillation (AO) index by phase

\begin{tabular}{|c|c|c|c|c|c|c|c|c|c|c|c|}
\hline \multicolumn{4}{|c|}{$\longrightarrow \mathrm{AO}^{+}$} & \multicolumn{4}{|c|}{$\mathrm{AO}^{-}$} & \multicolumn{4}{|c|}{$-\mathrm{AO}^{\mathrm{Neu}}$} \\
\hline Dec & Jan & Feb & Mar & Dec & Jan & Feb & Mar & Dec & Jan & Feb & Mar \\
\hline 1900 & 1901 & 1903 & 1903 & 1899 & 1900 & 1900 & 1899 & 1904 & 1899 & 1899 & 1901 \\
\hline 1902 & 1904 & 1905 & 1907 & 1901 & 1912 & 1901 & 1900 & 1906 & 1902 & 1904 & 1902 \\
\hline 1905 & 1905 & 1910 & 1911 & 1903 & 1915 & 1902 & 1909 & 1908 & 1903 & 1906 & 1904 \\
\hline 1912 & 1908 & 1911 & 1913 & 1907 & 1917 & 1912 & 1915 & 1911 & 1906 & 1907 & 1905 \\
\hline 1914 & 1910 & 1913 & 1918 & 1909 & 1918 & 1919 & 1916 & 1913 & 1907 & 1908 & 1906 \\
\hline 1919 & 1911 & 1914 & 1920 & 1910 & 1919 & 1924 & 1919 & 1918 & 1909 & 1909 & 1908 \\
\hline 1921 & 1914 & 1916 & 1921 & 1915 & 1922 & 1929 & 1924 & 1922 & 1913 & 1915 & 1910 \\
\hline 1924 & 1916 & 1918 & 1926 & 1916 & 1929 & 1933 & 1925 & 1923 & 1924 & 1917 & 1912 \\
\hline 1929 & 1920 & 1920 & 1927 & 1917 & 1931 & 1936 & 1928 & 1926 & 1926 & 1921 & 1914 \\
\hline 1931 & 1921 & 1922 & 1929 & 1920 & 1936 & 1940 & 1931 & 1928 & 1933 & 1923 & 1917 \\
\hline 1932 & 1923 & 1928 & 1938 & 1925 & 1939 & 1941 & 1932 & 1930 & 1935 & 1925 & 1922 \\
\hline 1936 & 1925 & 1934 & 1943 & 1927 & 1940 & 1942 & 1937 & 1933 & 1938 & 1926 & 1923 \\
\hline 1941 & 1927 & 1935 & 1945 & 1935 & 1941 & 1946 & 1940 & 1934 & 1946 & 1927 & 1930 \\
\hline 1943 & 1928 & 1937 & 1948 & 1937 & 1942 & 1947 & 1941 & 1939 & 1947 & 1930 & 1933 \\
\hline 1948 & 1930 & 1939 & 1953 & 1938 & 1943 & 1952 & 1947 & 1940 & 1948 & 1931 & 1934 \\
\hline 1951 & 1932 & 1943 & 1954 & 1945 & 1945 & 1955 & 1951 & 1942 & 1950 & 1932 & 1935 \\
\hline 1953 & 1934 & 1948 & 1956 & 1946 & 1953 & 1956 & 1952 & 1944 & 1951 & 1938 & 1936 \\
\hline 1957 & 1937 & 1949 & 1959 & 1947 & 1955 & 1957 & 1955 & 1949 & 1952 & 1944 & 1939 \\
\hline 1971 & 1944 & 1950 & 1963 & 1950 & 1956 & 1958 & 1957 & 1954 & 1954 & 1945 & 1942 \\
\hline 1972 & 1949 & 1959 & 1967 & 1952 & 1958 & 1960 & 1958 & 1955 & 1967 & 1951 & 1944 \\
\hline 1974 & 1957 & 1961 & 1968 & 1958 & 1959 & 1963 & 1960 & 1956 & 1968 & 1953 & 1946 \\
\hline 1975 & 1962 & 1967 & 1973 & 1961 & 1960 & 1965 & 1962 & 1959 & 1974 & 1954 & 1949 \\
\hline 1979 & 1964 & 1973 & 1976 & 1966 & 1961 & 1966 & 1965 & 1960 & 1971 & 1962 & 1950 \\
\hline 1982 & 1973 & 1975 & 1978 & 1968 & 1963 & 1968 & 1966 & 1962 & 1972 & 1964 & 1961 \\
\hline 1983 & 1975 & 1976 & 1982 & 1969 & 1965 & 1969 & 1969 & 1963 & 1976 & 1972 & 1964 \\
\hline 1984 & 1983 & 1982 & 1985 & 1976 & 1966 & 1970 & 1970 & 1964 & 1978 & 1974 & 1972 \\
\hline 1986 & 1984 & 1989 & 1986 & 1978 & 1969 & 1971 & 1971 & 1965 & 1981 & 1979 & 1974 \\
\hline 1988 & 1988 & 1990 & 1989 & 1981 & 1970 & 1977 & 1980 & 1967 & 1986 & 1980 & 1975 \\
\hline 1990 & 1989 & 1992 & 1990 & 1985 & 1977 & 1978 & 1981 & 1970 & 1987 & 1981 & 1977 \\
\hline 1991 & 1990 & 1993 & 1992 & 1995 & 1979 & 1983 & 1984 & 1973 & 1994 & 1984 & 1979 \\
\hline 1992 & 1991 & 1995 & 1993 & 1996 & 1980 & 1985 & 1987 & 1977 & 1995 & 1988 & 1983 \\
\hline 1994 & 1992 & 1996 & 1994 & 2000 & 1982 & 1986 & 1996 & 1980 & 1997 & 1991 & 1988 \\
\hline 1998 & 1993 & 1997 & 1997 & 2001 & 1985 & 1987 & 1999 & 1987 & 1999 & 1994 & 1991 \\
\hline 1999 & 2000 & 1998 & 2002 & 2002 & 1996 & 2004 & 2001 & 1989 & 2001 & 2001 & 1995 \\
\hline 2003 & 2002 & 1999 & 2003 & 2005 & 1998 & 2005 & 2005 & 1993 & 2003 & 2003 & 1998 \\
\hline 2004 & 2006 & 2000 & 2004 & & 2004 & 2007 & 2006 & 1997 & 2005 & 2006 & 2000 \\
\hline 2006 & 2007 & 2002 & 2007 & & & & & & & & \\
\hline
\end{tabular}

equatorial Pacific basin, such as the PNA region. A series of average composite maps often used to explore such nonlinear teleconnections were used here to explore the state of SPI and $500 \mathrm{hPa}$ geopotential height anomalies during the various AO-ENSO combinations. Student's $t$-test, along with resampling procedures (Wilks 1995), was used to assess the statistical significance of the SPI and height anomaly differences between the various AO-ENSO combinations at the $95 \%$ confidence level.

\section{RESULTS}

\subsection{Intraseasonal variability of the AO and the ENSO}

The number of months and years within each of the 9 AO-ENSO combinations are shown in Table 4 and Fig. 1. No inclination for a specific AO phase exists during ENSO-neutral years that show 77, 78, and
$80 \mathrm{mo}$ in the $\mathrm{AO}^{+}, \mathrm{AO}^{-}$, and $\mathrm{AO}^{\mathrm{Neu}}$ phases, respectively (Fig. 1c). With the exception of February, when $46 \%$ of La Niñas coincided with the positive phases of the AO, none of the 3 phases occurred more frequently during La Niña years than in other months (Fig. 1b), although positive phases of the AO have occurred significantly more frequently than have negative phases, as shown by a $\chi^{2}$ test at the $95 \%$ confidence level (Wilks 1995). During El Niño winters, $44 \%$ of the months between January and March were accompanied by negative

Table 4. Number of winter months (DJFM) classified within each Arctic OscillationIEl Niño-Southern Oscillation (AOIENSO) combination

\begin{tabular}{|lccc|} 
& $\mathrm{AO}^{+}$ & $\mathrm{AO}^{-}$ & $\mathrm{AO}^{\mathrm{Neu}}$ \\
\hline El Niño & 34 & 38 & 32 \\
La Niña & 37 & 26 & 32 \\
ENSO neutral & 77 & 78 & 80 \\
\hline
\end{tabular}


(a) El Niño

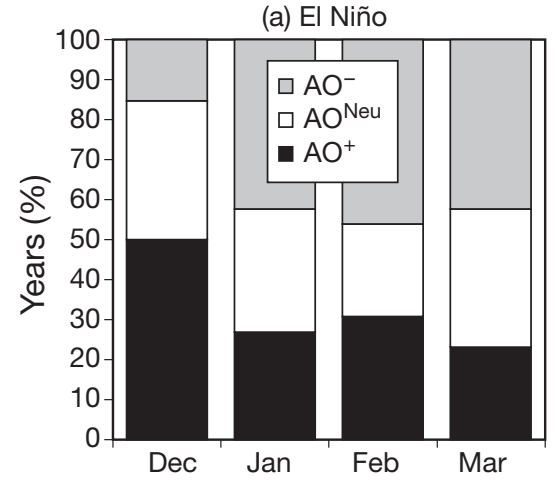

(b) La Niña

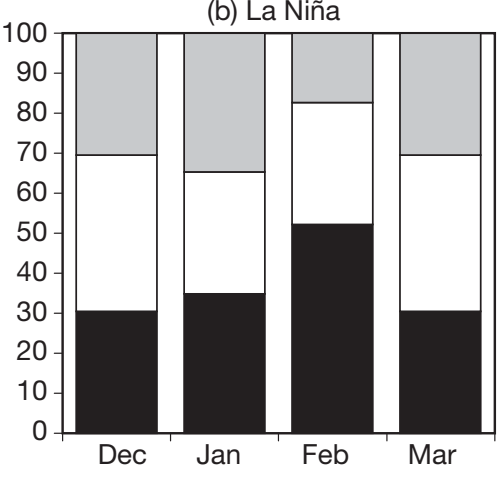

(c) ENSO-neutral

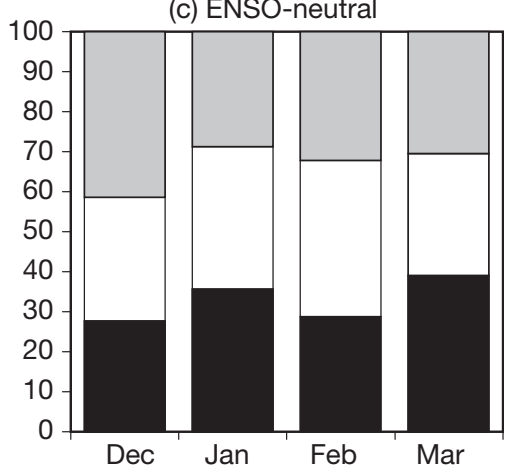

Fig. 1. Percent of ENSO years between 1899 and 2007 that coincided with positive $\left(\mathrm{AO}^{+}\right)$, negative $\left(\mathrm{AO}^{-}\right)$, and $\mathrm{AO}^{-n e u t r a l}\left(\mathrm{AO}^{\mathrm{Neu}}\right)$ phases by month

phases of the $\mathrm{AO}$, and a $\chi^{2}$ test shows the negative phases to be significantly more frequent than the positive ones at the $90 \%$ confidence level.

The AO also shows considerable intraseasonal or month-to-month variability. The index remained in a single phase throughout the 4 winter months in 30 of the past 109 winters $(28 \%)$. When the AO indices were classified into positive and negative phases according to the 33rd and 66th percentiles, only $9 \mathrm{yr}(8.3 \%)$ showed the same AO phase throughout the winter, 7 of which were in the positive phase and 2 of which were in the negative phase. The AO switched from one phase to another during the same winter in $52(48 \%)$ of the $109 \mathrm{yr}$. This month-to-month variation in the AO during a single winter period has been observed throughout this century. Until the mid-1950s, the variation occurred randomly from one year to another. From 1955 through 1969, between the late 1970s through the late 1980s, and after 1996 this intraseasonal phase-switching became more common as almost every winter experienced significant variation in the AO phase from one month to another. From 1970 through 1978 and between 1988 and 1996, the AO remained in 1 phase throughout a single winter more often. These observations demonstrate the need to examine the AO time series on a month-by-month basis within a given winter season.

\subsection{Isolated effect of the $A O$}

Fig. 2 depicts the effect of the AO on midtropospheric winter circulation without the influence of the ENSO. Observed is the expected dipole structure, with opposing height anomalies in the high and mid-latitudes of the NH, also shown by Thompson \& Wallace (1998) (Fig. 2a,b). Significant centers of action of opposing sign are located over Greenland and the mid-latitudinal Atlantic basin, with smaller anomalies of similar sign to those in the Atlantic observed over the North Pacific Ocean (Fig. 2c). Such anomaly patterns reflect modification in the Aleutian Low, the Bermuda high, the strength of the NH circumpolar vortex, and coincide with an alteration of the expected winter precipitation patterns over the eastern USA as demonstrated by the SPI.

The spatial patterns of the SPI associated with the extreme phases of the AO are not simple mirror images of each other (Fig. 3). The positive phase of the AO significantly alters winter SPI regimes in limited areas of the eastern USA (Fig. 3a). Statistically significant differences in SPI are observed throughout northern parts of North Dakota and Minnesota, where conditions are unseasonably drier, and throughout northern Oklahoma and southern Kansas, where wetter-than-expected conditions prevail at this time. When the AO is negative (Fig. 3b), significant precipitation anomalies are observed in 2 large areas. Winters become anomalously dry throughout the region extending from southeast Oklahoma, through Arkansas, and into the Tennessee River and lower Ohio River Valley regions. At the same time, wetter-than-expected conditions are observed throughout Florida. Overall, winter SPI regimes are significantly effected by the extreme phases of the AO in 3 major areas (Fig. 3c): the interior upper Midwest, an area that spans western Minnesota and South Dakota; the Florida peninsula; and throughout the interior of the area extending towards the northeast from Texas and into the Great Lakes region. When the AO is positive, the combined presence of a strong polar vortex that keeps cold and dry air well to the north of the study area coupled with a well-developed Bermuda high over the Atlantic basin and eastern USA promotes the influx of moist air into the interior portions of the eastern USA from the Gulf of Mexico (Fig. 2c) (Thompson \& Wallace 1998). 


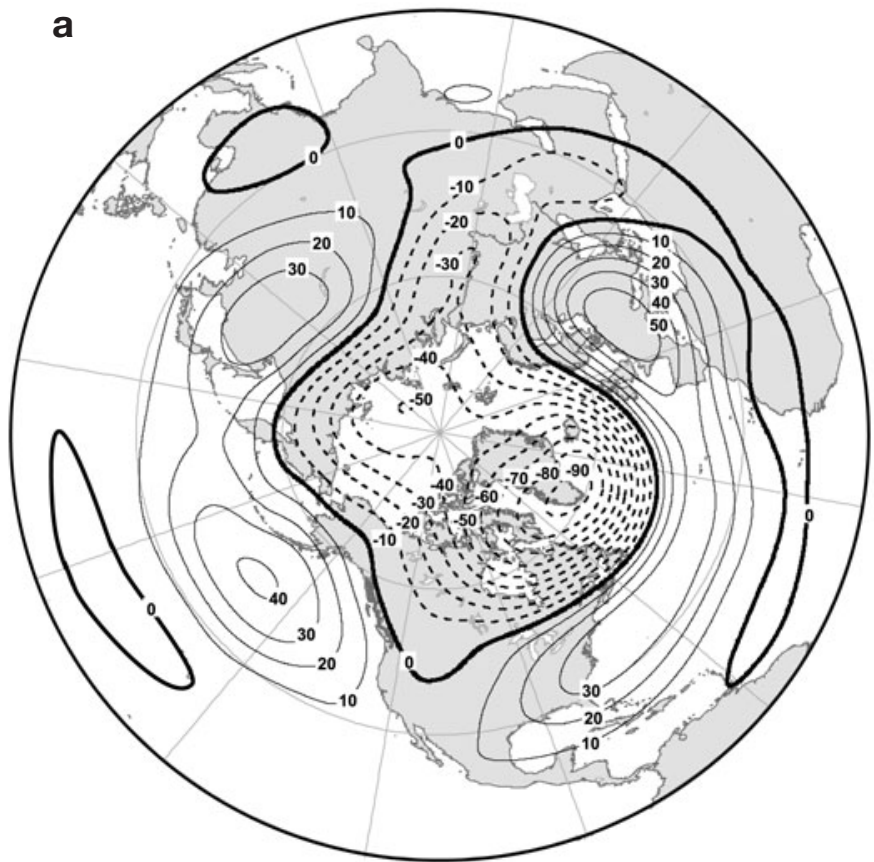

Fig. 2. The $500 \mathrm{hPa}$ geopotential height anomalies (m): (a) $\mathrm{AO}^{+} \mid \mathrm{ENSO}^{\mathrm{Neu}}$, (b) $\mathrm{AO}^{-} \mid \mathrm{ENSO}^{\mathrm{Neu}}$, and (c) difference in height anomalies during positive and negative phases of the $\mathrm{AO}$ when ENSO is neutral $\left(\mathrm{AO}^{+} \mid \mathrm{ENSO}^{\mathrm{Neu}}\right.$ and $\mathrm{AO}^{-} \mid \mathrm{ENSO}^{\mathrm{Neu}}$ ). Darkly shaded areas: significant at the $95 \%$ confidence level

\subsection{Effect of the AO on ENSO-related precipitation}

Winter SPI regimes associated with El Niño are distinct during various phases of the AO (Fig. 4a to f). Without the influence of the AO, high SPI values are present in Florida and throughout Texas and the Great Plains region south of South Dakota, where wetterthan-expected conditions prevail (Fig. 4a). When the AO becomes positive, the wet conditions observed in Florida spread into the interior and along the eastern seaboard to Virginia (Fig. 4b), the most significantly affected states being Alabama, Georgia, and South Carolina (Fig. 4d).

The presence of the negative phase of the AO coincides with a significant 'drying' of a large area spanning towards the northeast from eastern Kansas to the Great Lakes via Missouri, Illinois, Indiana, Ohio, Kentucky, and eastern Pennsylvania (Fig. 4c). Also modified are precipitation patterns across southern Florida, where the typically wet conditions associated with El Niño become even wetter when $\mathrm{AO}$ is in its negative phase.

Fig. 4f reveals a vast area with significantly different El Niño-related SPI regimes associated with the 2 extreme phases of the AO. This region spans eastwards of the Great Plains and is marked by signifi-
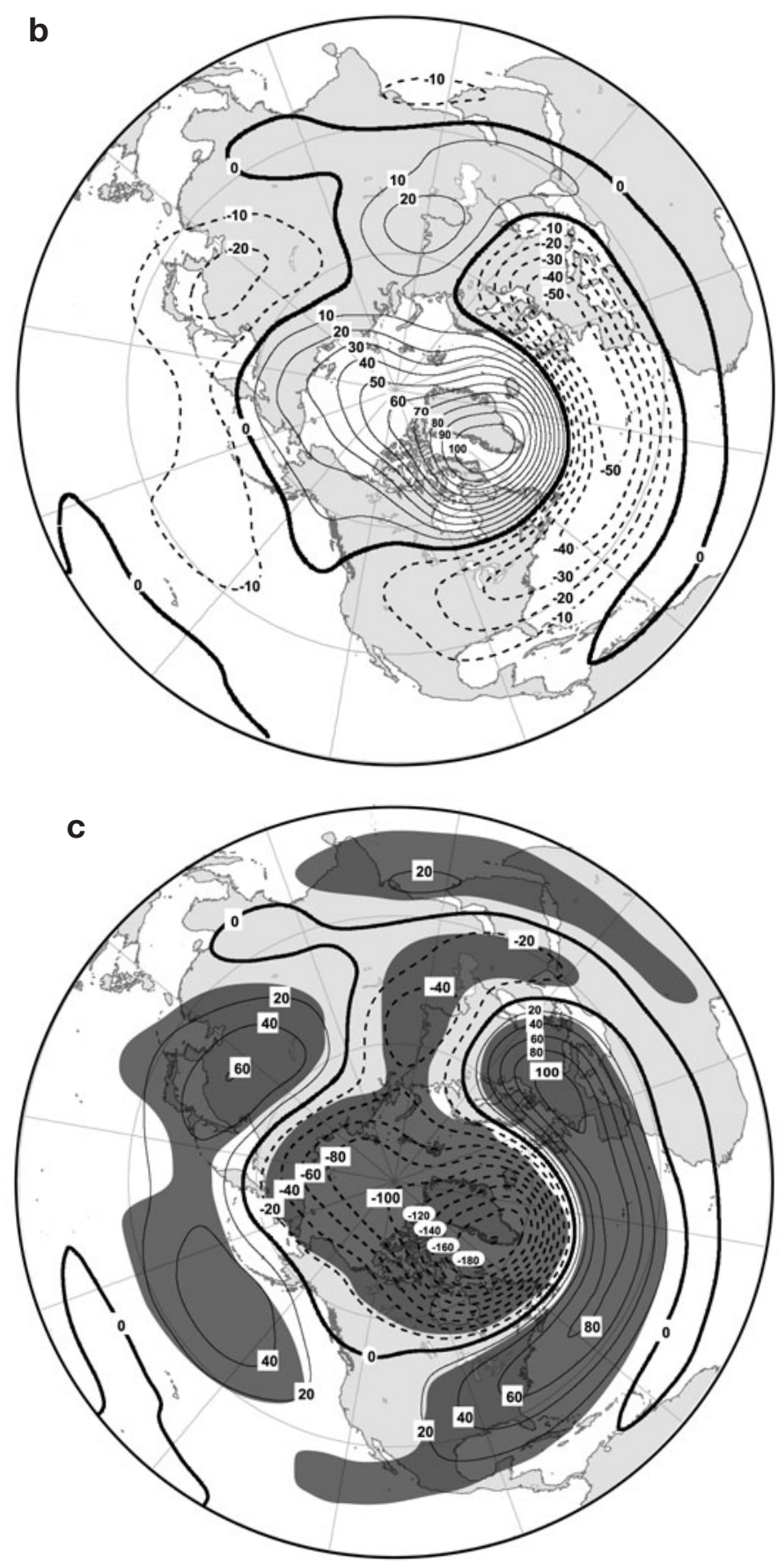

cantly wetter El Niño winters during the positive phase of the AO. Precipitation of the Florida Peninsula is also distinctly affected during El Niño years, with significantly drier winters present during the positive phase.

When the AO is in its neutral phase, La Niña winters are typically marked by wet conditions throughout the southern portions of the Ohio Valley, in the Tennessee Valley, around the northern Great Lakes of Wisconsin, Michigan, Minnesota, and in North Dakota (Fig. 5a). At this time, conditions are dry throughout 

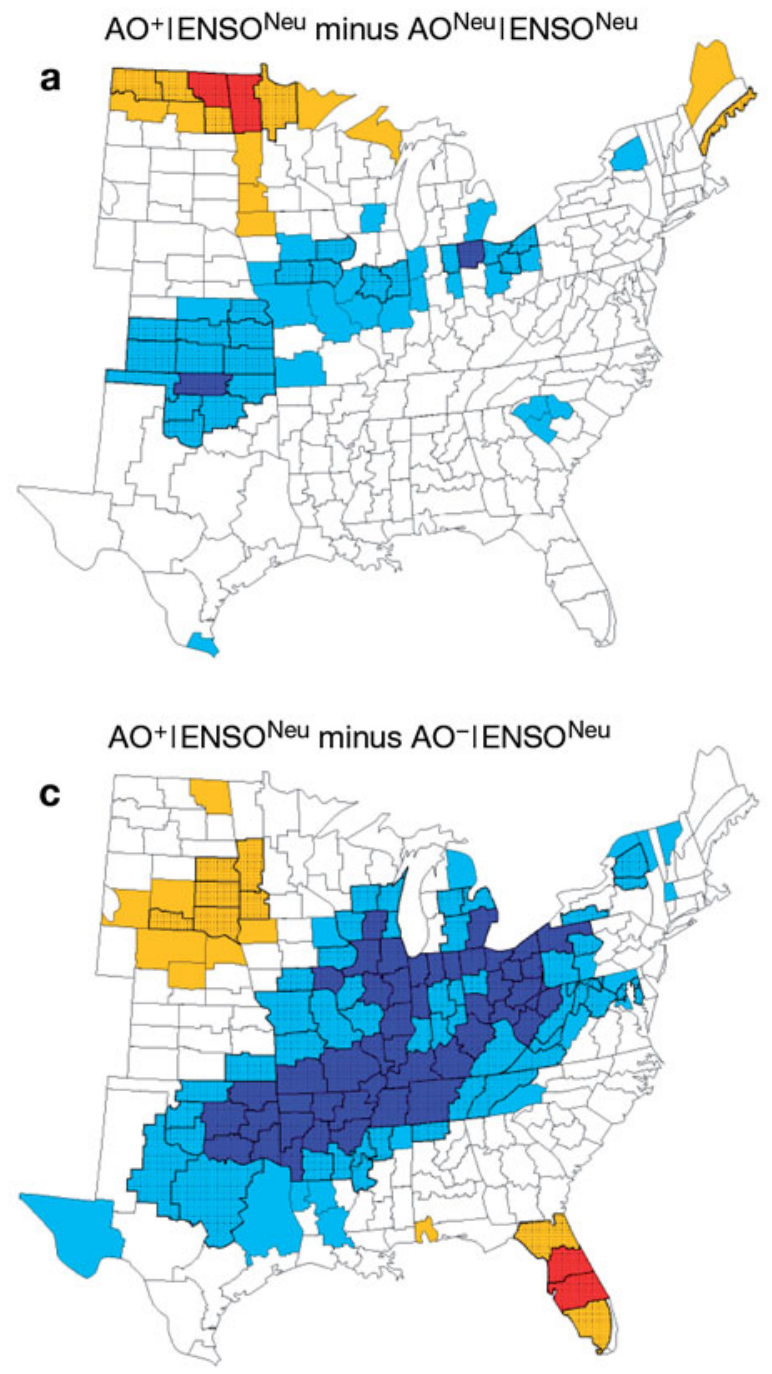

Texas, along the Gulf coast, and in Florida. With the exception of Florida, the SPI returns to seasonal levels when the AO becomes positive (Fig. 5b). Fig. 5d shows that areas with significant effects on SPI regimes when the AO is positive are small in extent and randomly scattered. Precipitation conditions return to seasonal values throughout the study area during months when the AO is negative (Fig. 5a,c,e). Fig. 5f shows areas with markedly different La Niña-related SPI regimes to be associated with the 2 extreme phases of the AO. Included are regions of southern Louisiana, Alabama, Georgia, and northern Florida, where winters are significantly drier during the positive phase of the AO. At the same time, wetter La Niña winters are observed when the $\mathrm{AO}$ is in its positive phase in the interior of the study area, with significant differences being observed across the northern sections of the Ohio Valley.

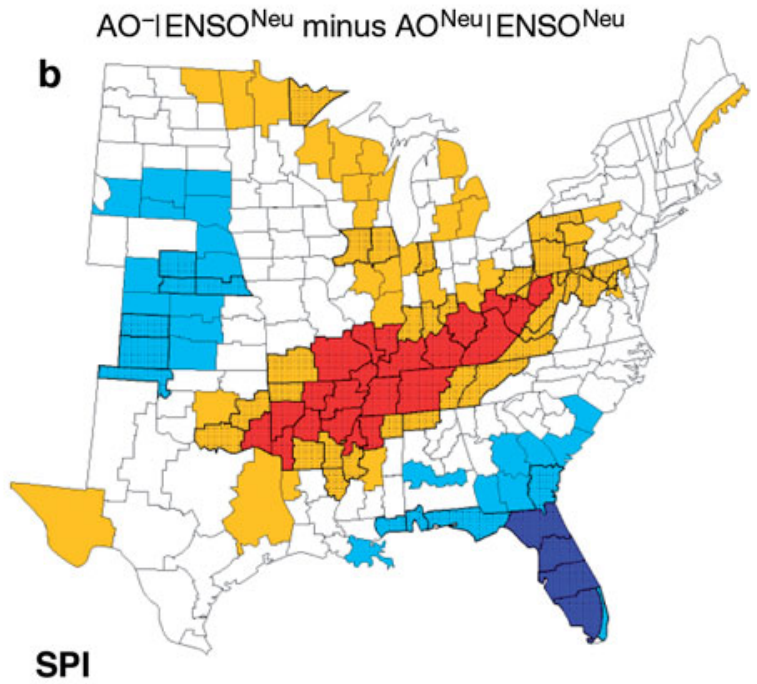

$\square<-0.40$
$\square<-0.20$
$\square$
0
$\square 0.20$
$>0.40$

Fig. 3. Differences in mean standardized precipitation index (SPI; $\sigma$ ) depicting the impact of the various phases of the AO under ENSOneutral conditions: when the $\mathrm{AO}$ is (a) positive, (b) negative, and (c) between positive and negative phases. Dotted and outlined areas: significant differences at the $95 \%$ confidence level

Fig. 6a,b reveal the distinct effect of the 2 extreme phases of the AO on ENSO-related SPI. When the AO is positive, El Niño precipitation regimes are significantly different from those observed during La Niña along the east coast from Florida to New England, along the Gulf States, throughout Texas, and the southern Great Plains. When compared to La Niña, these areas are significantly wetter during El Niño years. Also, distinctly affected are limited sections of the northern Ohio Valley, where El Niños are significantly drier in comparison to La Niñas (Fig. 6a). When the AO is negative, the effected area around the Great Lakes markedly expands to include the northern sections of the Midwest around Lake Superior, the central Midwest, and the Ohio Valley. At the same time, the large area of significantly wetter conditions observed during El Niño when the AO is positive becomes limited to Florida, southern Georgia, the southern Gulf States and Texas, when the AO becomes negative (Fig. 6b).

\subsection{Atmospheric circulation}

\subsubsection{Isolated ENSO teleconnections}

Atmospheric conditions associated with ENSOrelated SPI regimes were examined using average composite maps of $500 \mathrm{hPa}$ geopotential height sur- 

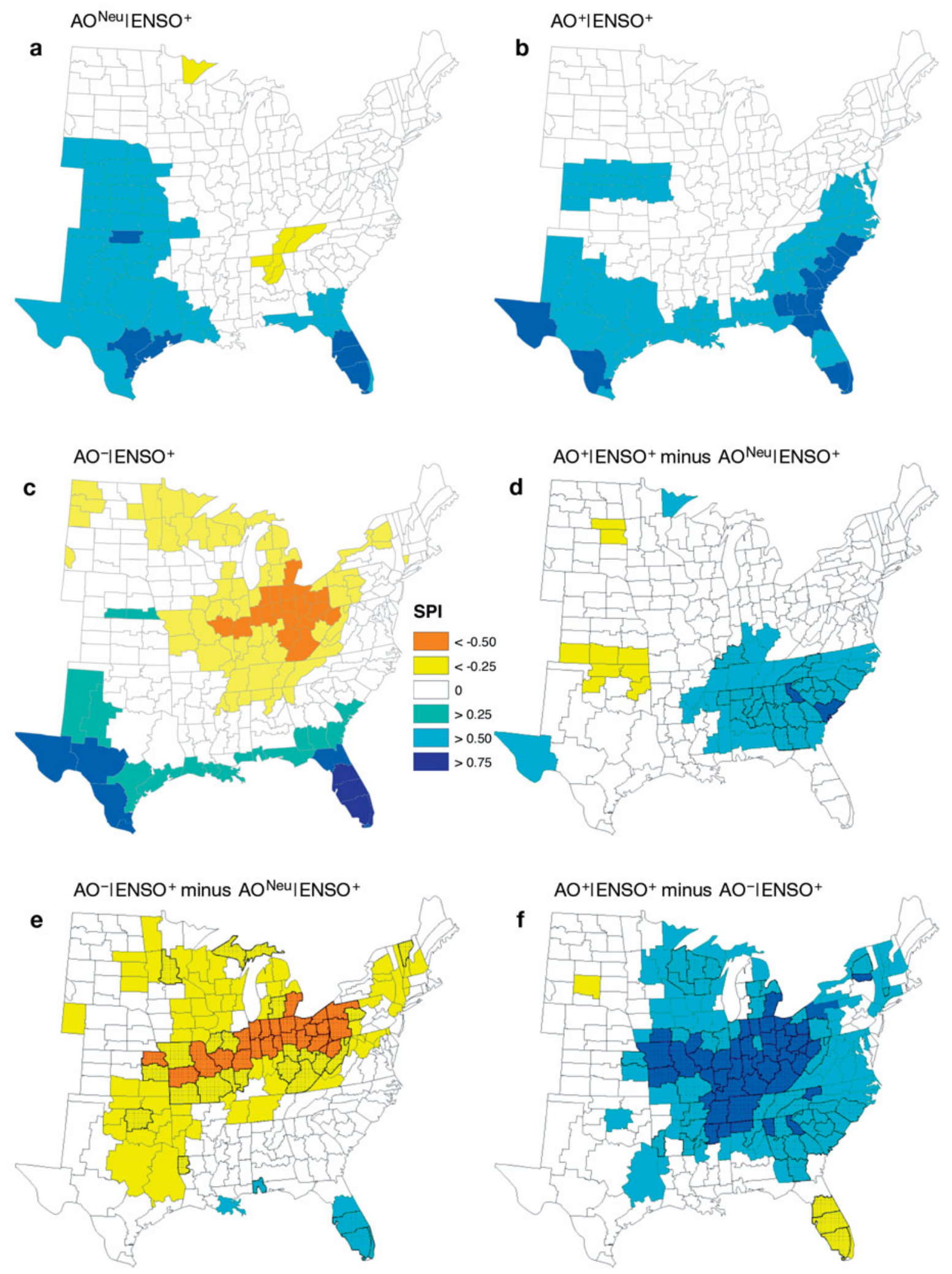

Fig. 4. Effect of the AO on mean El Niño-related SPI $(\sigma)$ when (a) AO is neutral, (b) AO is positive, (c) AO is negative; (d) difference between positive and neutral phases (effect of the positive phase of the AO), (e) difference between negative and neutral phases (effect of the negative phase of the AO), and (f) overall effect of the extreme phases of AO. Dotted and outlined areas: significant differences at the $95 \%$ confidence level 

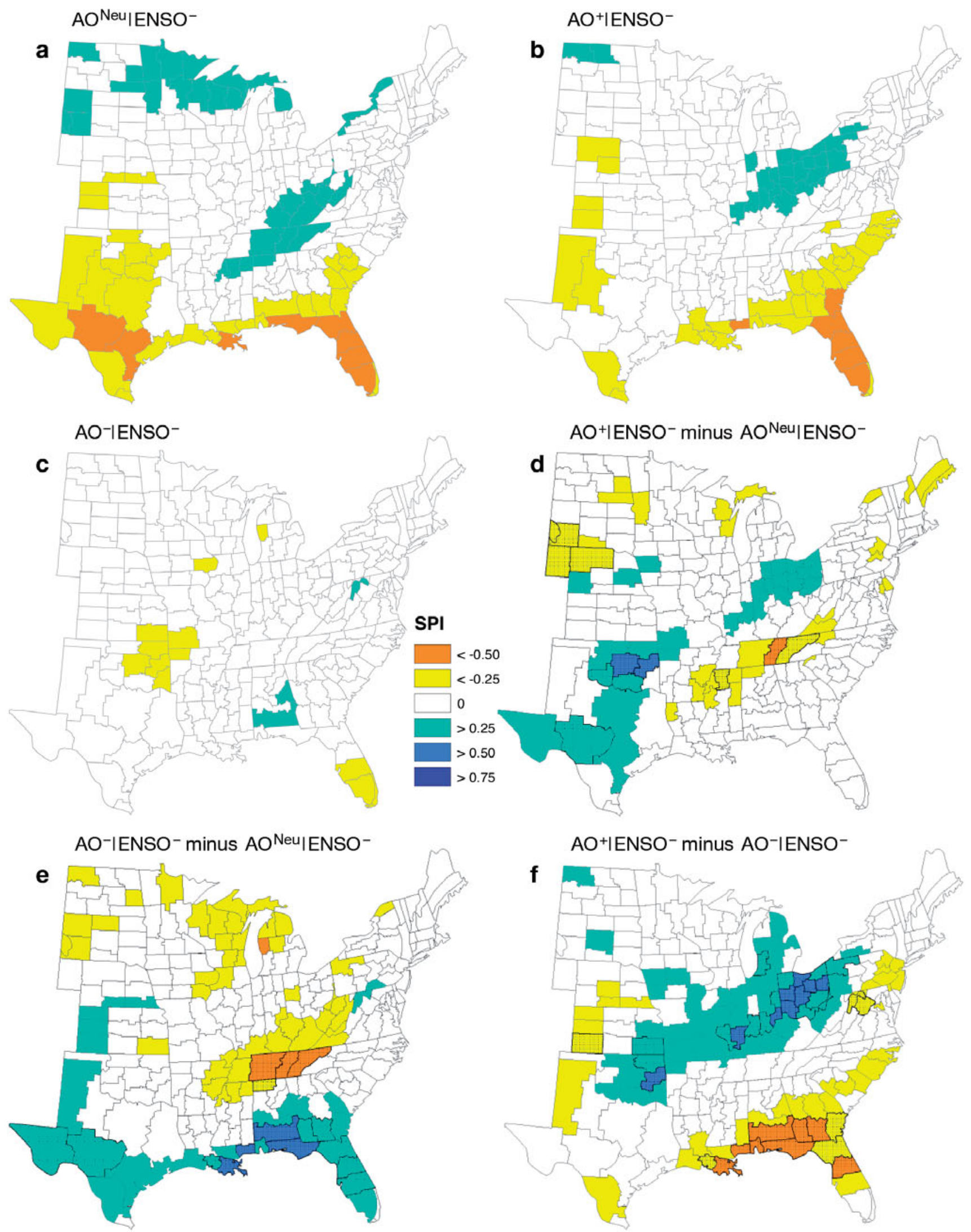

Fig. 5. Effect of the AO on La Niña-related SPI $(\sigma)$ for the same conditions as described in Fig. 4 

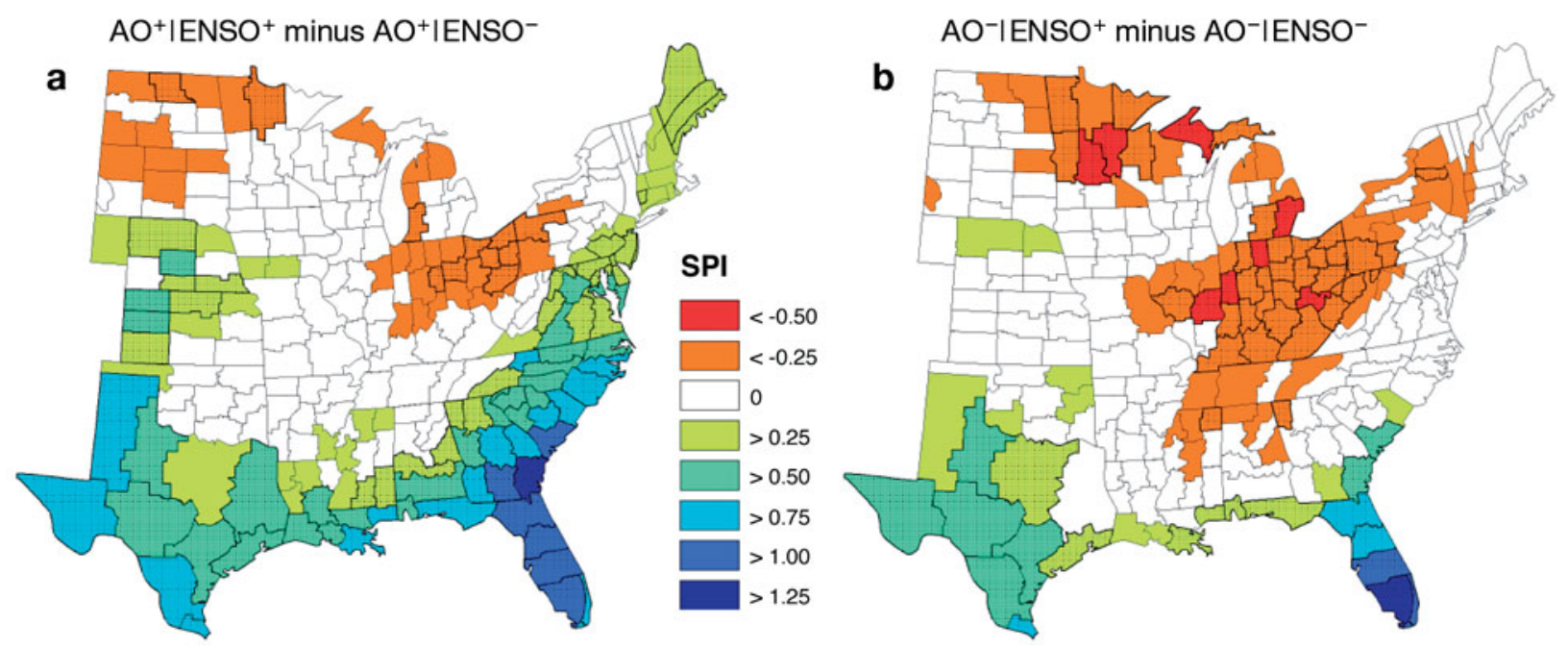

Fig. 6. Difference between mean El Niño- and La Niña-related SPI regimes ( $\sigma$ ) during winter months when: the AO is (a) positive or (b) negative. Dotted and outlined areas: significant differences at the $95 \%$ confidence level

faces as they help define the migration paths of air masses and storms that control temperature and precipitation over the PNA region (Diaz et al. 2001). The typical El Niño and La Niña signatures in the midtropospheric field have been well documented over the PNA region and are evident during AO-neutral periods. El Niño events coincide with a circulation pattern that resembles the positive phase of the PNA pattern (Fig. 7a) that favors a strong meridional flow of the polar jet stream and winter storm tracks across the northern sections of the USA and a strong subtropical jet flow across the south. The synoptic circulation pattern during La Niña occurrences typically resembles the reverse phase of the PNA reflective of a zonal westto-east jet and storm track flow over the North American continent (Fig. 7b).

\subsubsection{Effect of the AO on ENSO-related atmospheric circulation}

The positive phase of the AO alters the expected synoptic conditions over the PNA region during El Niño winters (Figs. 7a,c \& 8a). Height anomalies drop over the high latitudes of the NH and Eurasia, with significant declines in pressures observed over Greenland and central Eurasia. Geopotential heights rise throughout the mid-latitudes, significantly over Europe and just off the northeastern coast of USA. The presence of a well-developed high pressure system over the North American continent, including the eastern USA and the western Atlantic basin, promotes the influx of moist air into the study area from the east.
Mid-tropospheric height anomalies decline (rise) throughout the mid- (high-)latitudes of the $\mathrm{NH}$ during El Niño years when the AO is negative (Figs. 7a,d \& $8 b)$. The decline in pressure is statistically significant over the northwestern sections of the North Pacific and Asia, throughout the Atlantic basin and over Mexico. Significant rise in geopotential heights spans an area around the polar cap from Beaufort and the Siberian Sea to the Greenland Sea and Labrador. The circulation is marked by an intensified Aleutian Low that extends west past the dateline and a considerably weakened Bermuda High over the Atlantic. The highpressure cell typically situated over the interior of Canada is displaced to the north and east, reaching maximum intensity over eastern Canada and Greenland. The intensification of the atmospheric circulation over the North Pacific can be attributed to the anomalously weak polar vortex and increased meridional flow (e.g. Marshall et al. 2001) in conjunction with the expected circulation anomalies associated with El Niño (e.g. Wallace \& Gutzler 1981, Bond \& Harrison 2006).

The mid- (high-)latitudes are dominated by positive (negative) height anomalies during La Niña winters when the AO is in its positive phase, enhancing the expected atmospheric flow over the North Pacific and southeastern USA (Figs. 7b,e \& 8c). A statistically significant rise in geopotential heights is observed over the midlatitudes of the western North Pacific, the Atlantic basin and over the western interior of the USA. These changes are coupled with a significant decline in height anomalies over the Arctic Ocean. When the AO is negative, the positive height anomalies typically present

Fig. 7. Mean 500 hPa geopotential height anomalies (m) associated with various AO-ENSO combinations: (a) $\mathrm{AO}^{\mathrm{Neu}} \mid \mathrm{ENSO}^{+}$, (b) $\mathrm{AO}^{\mathrm{Neu}} \mid \mathrm{ENSO}^{-}$, (c) $\mathrm{AO}^{+} \mid \mathrm{ENSO}^{+}$, (d) $\mathrm{AO}^{-} \mid \mathrm{ENSO}^{+}$, (e) $\mathrm{AO}^{+} \mid \mathrm{ENSO}^{-}$, (f) $\mathrm{AO}^{-} \mid \mathrm{ENSO}^{-}$ 

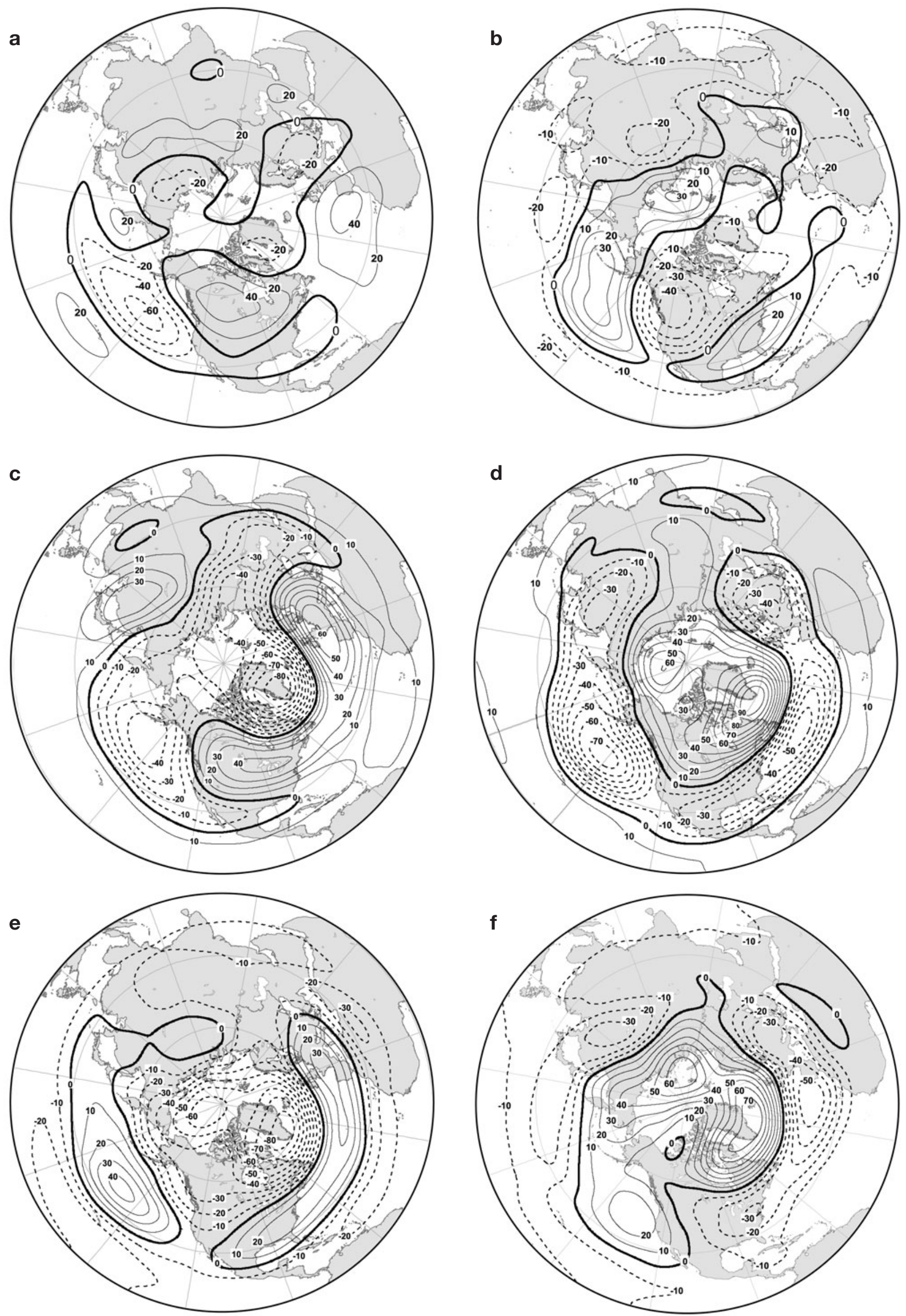

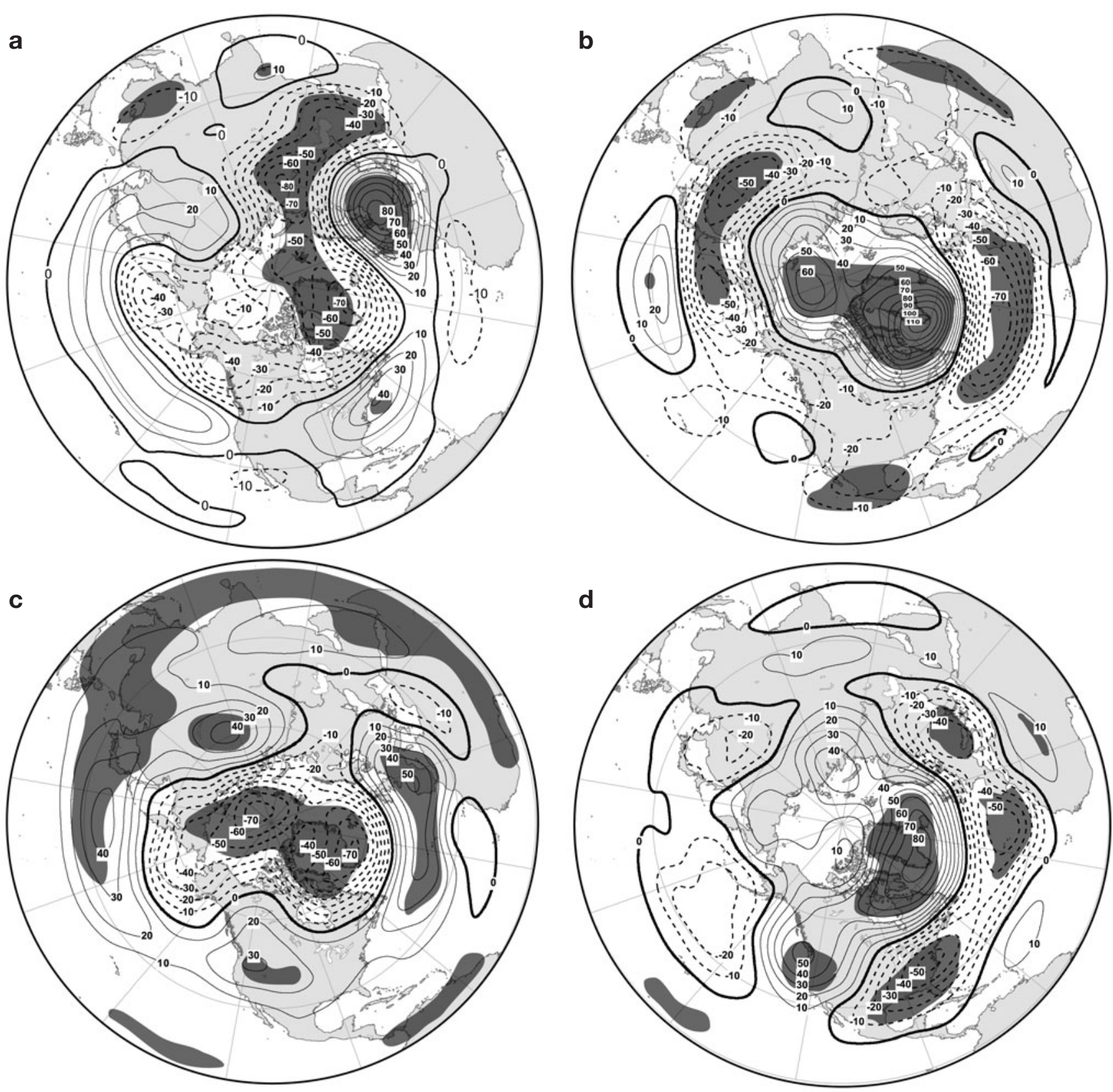

Fig. 8. Effect of the AO on the mean $(\mathrm{a}, \mathrm{b})$ El Niño- and $(\mathrm{c}, \mathrm{d})$ La Niña-related mid-tropospheric height $(\mathrm{m})$ : $(\mathrm{a}, \mathrm{c})$ difference between positive and neutral phases (effect of the positive phase of the AO), (b,d) difference between negative and neutral phases (effect of the negative phase of the AO). Darkly shaded areas: significant at the $95 \%$ confidence level

over the central North Pacific and over the southeastern USA and the western Atlantic fall as the Aleutian Low regains strength over the central North Pacific and the influence of the Bermuda High weakens over the Atlantic (Figs. 7b,f \& 8d). The drop (rise) in height anomalies is statistically significant over the study area and most of the Atlantic basin and Europe (eastern North Pacific and western USA, Labrador, and Greenland). The resulting synoptic pattern closely represents that of a typical winter circulation pattern over the PNA region and the study area.

\section{DISCUSSION AND CONCLUSIONS}

Dethloff et al. (2006) and Nakamura et al. (2006) show the effect of the state of the atmospheric flow over high latitudes of the $\mathrm{NH}$ upon remote climates around the globe. By separating ENSO events according to the sign of the $\mathrm{AO}$, the present study adds to this body of knowledge by demonstrating that the state of the NH atmospheric circulation, as highlighted by the AO, influences the expected North American teleconnection patterns that emanate from the tropical Pacific 
basin during ENSO years. Such changes, in turn, significantly modify surface precipitation patterns across the eastern USA, as described by the SPI.

Between January and March, El Niño winters are more often than not accompanied by the negative phase of the AO. This observation is consistent with results by Taguchi \& Hartmann (2006), who showed that sudden stratospheric warming indicative of a decrease in the NAM index to strong negative values is more frequent during El Niño winters than during La Niña. Labitzke \& van Loon (1999) showed that the polar vortex tends to be weaker during El Niño winters and stronger during La Niña. A month-to-month examination of the AO revealed considerable intraseasonal variation of the index during the winter season, also found by Thompson \& Wallace (2000) and Liu et al. (2007), who demonstrated that the AO typically switches sign in late winter. This high intra-seasonal variability observed in the index of the AO can influence month-to-month variation of ENSO teleconnections across the PNA region and thus needs to be taken into account when assessing the interaction between the AO and ENSO during the winter season.

The precise position and strength of the troughs and ridges of the mid-tropospheric circulation over the PNA region strongly influence the winter precipitation regimes across the USA (Yarnal \& Leathers 1988). More recently, Li et al. (2006) pointed out the importance of the state of the Aleutian Low over the Gulf of Alaska to the development of an anomalous high over the USA and the entire Rossby wave train pattern over the PNA region, along with the manifestation of the surface weather and climate anomalies during ENSO events. The results of the present study confirm these claims. The most pronounced and influential to the climate of the USA are modifications in atmospheric circulation over the mid- and high latitudes of the North Pacific and the North American continent, specifically those related to the strength and position of the Aleutian Low, the Canadian High, and the Bermuda High. El Niño-related precipitation regimes are more extensively affected by the AO than are precipitation patterns associated with La Niña. As well, the negative phase of the AO more significantly modifies ENSOrelated precipitation and circulation regimes across the eastern USA than does the positive phase of the index.

Wetter-than-expected winters are observed during El Niño events along the southeast coast when the AO is in its positive phase. These conditions coincide with a weakened Aleutian Low and a strong ridge over the northeast USA and the North Atlantic, reflective of a well-developed Bermuda High. At this time, the upper air flow over the study area is dominated by easterly wind flow that advects moist air into the region. Bond \& Harrison (2006) found that when the AO is positive, the general circulation flow associated with El Niño is gen- erally weaker and less meridional in comparison to times when the AO is negative. When the AO is negative, El Niño winters are significantly drier than expected throughout large sections of the central Midwest and the Ohio Valley, while southern Florida is significantly wetter than during El Niño years when the AO is neutral. At this time, the synoptic and surface SPI conditions resemble those of an enhanced El Niño. Such conditions coincide with the influx of northwesterly air flow into the northern USA and a well-developed subtropical jet, that together bring cold and dry air into the mid-section of the study area and wet conditions to the south, respectively. These results are in general agreement with those of Bond \& Harrison (2006), who found the effects of El Niño to be much stronger when the $\mathrm{AO}$ is in its negative phase. The positive phase of the AO shows little effect on the expected La Niña SPI and atmospheric circulation regimes over the eastern USA and the PNA region, respectively. Significant modifications of the SPI regimes associated with La Niña months when the AO is negative are limited to the southeastern sections of the Gulf of Mexico, with the atmospheric circulation regimes resembling those of a typical winter.

The present study aimed to isolate the combined effects of the AO and ENSO on winter precipitation and atmospheric circulation across the eastern USA. In addition, other potentially important modes of winter climate variability influence the climate during ENSO years. Among these are the PDO (e.g. Gershunov \& Barnett 1998), the AMO (e.g. Enfield et al. 1999), and long-term climate trends (e.g. Diaz et al. 2001). As a result the documented precipitation and associated circulation patterns in the present study will be influenced by other factors as well and cannot be strictly attributed to the $\mathrm{AO}$ alone.

The results of this study display evidence of considerable interaction between 2 principal modes of extratropical variability, ENSO and the AO. The state of the AO significantly influences ENSO-related teleconnection patterns and associated precipitation regimes across the eastern USA during winter months. The high month-tomonth variability in the index of the AO needs to be considered when assessing its interaction with ENSO. This knowledge contributes to our understanding of interENSO variability of remote teleconnections across the PNA region (e.g. Hoerling \& Kumar 1997, Hoerling et al. 1997), and, in turn, can have a positive effect on our ability to provide better winter climate forecasts across the eastern USA during ENSO episodes, especially once the state of the AO can be forecasted with appreciable skill for a lead time of one or more seasons.

Acknowledgements. The author thanks the anonymous reviewers for their insightful comments, and Melissa Dougherty O'Hara for assistance with cartography. 


\section{LITERATURE CITED}

- Baldwin MP, Durkerton TJ (1999) Propagation of the Arctic Oscillation from the stratosphere to the troposphere. J Geophys Res 104:30,937-30,946

> Bond NA, Harrison DE (2006) ENSO's effect on Alaska during opposite phases of the Arctic Oscillation. Int J Climatol 26: 1821-1841

- Bronnimann S, Luterbacher J, Staehelin J, Svendby TM, Hansen G, Svenoe T (2004) Extreme climate of the global troposphere and stratosphere in 1940-42 related to El Niño. Nature 431:971-974

> Budikova D (2005) Impact of the Pacific Decadal Oscillation on relationships between temperature and the Arctic Oscillation in the USA in winter. Clim Res 29:199-208

> Dethloff K, Rinke A, Benkel A, Koltzow M and others (2006) A dynamical link between the Arctic and the global climate system. Geophys Res Lett 33:L03703

> Diaz HF, Hoerling MP, Eischeid JK (2001) ENSO variability, teleconnections and climate change. Int $\mathrm{J}$ Climatol 21: $1845-1862$

> Enfield DB, Mestas-Nuñez AM, Trimble PJ (2001) The Atlantic multidecadal oscillation and its relation to rainfall and river flows in the continental U.S. Geophys Res Lett 28:2077-2080

Frauenfeld OW, Davis RE (2000) The influence of El NiñoSouthern Oscillation events on the Northern Hemisphere $500 \mathrm{hPa}$ circumpolar vortex. Geophys Res Lett 27:537-540

$>$ Frauenfeld OW, Davis RE (2002) Midlatitude circulation patterns associated with decadal and interannual Pacific Ocean variability. Geophys Res Lett 29:2221

> Gershunov A, Barnett TP (1998) Interdecadal modulation of ENSO teleconnections. Bull Am Meteorol Soc 79:2715-2726

> Guttman NB, Quayle RG (1996) A historical perspective of US climate divisions. Bull Am Meteorol Soc 77:293-303

> Hamilton K (1993) An examination of observed Southern Oscillation effects in the Northern Hemisphere stratosphere. J Atmos Sci 50:3468-3473

Higgins RW, Leetmaa A, Xue Y, Barnston A (2000) Dominant factors influencing the seasonal predictability of U.S. precipitation and surface air temperature. J Clim 13:3994-4017

> Higgins RW, Silva VBS, Shi W, Larson J (2007) Relationships between climate variability and fluctuations in daily precipitation over the United States. J Clim 20:3561-3579

> Hoerling MP, Kumar A (1997) Why do North American climate anomalies differ from one El Niño event to another? Geophys Res Lett 24:1059-1062

- Hoerling MP, Kumar A, Zhong M (1997) El Niño, La Niña, and the nonlinearity of their teleconnections. J Clim 10:1769-1785

> Huang JP, Higuchi K, Shabbar A (1998) The relationship between the North Atlantic Oscillation and the El NiñoSouthern Oscillation. Geophys Res Lett 25:2707-2710

Kalnay E, Kanamitsu M, Kistler R, Collins W and others (1996) The NCEP/NCAR 40-year reanalysis project. Bull Am Meteorol Soc 77:437-471

Kaplan A, Cane M, Kushnir Y, Clement A, Blumenthal M, Rajagopalan B (1998) Analyses of global sea surface temperature 1856-1991. J Geophys Res 103:18,567-18,589

Labitzke K, van Loon H (1999) The stratosphere. Springer, New York

Leathers DJ, Yarnal B, Palecki MA (1991) The Pacific/North American teleconnection pattern and United States climate. I: Regional temperature and precipitation associations. J Clim 4:517-528

Li S, Hoerling MP, Peng S, Weickmann KM (2006) The annular response to tropical Pacific SST forcing. J Clim 19:1802-1819

Limpasuvan V, Hartmann DL (1999) Eddies and the annular modes of climate variability. Geophys Res Lett 26:3133-3136

Liu Z, Liu Y, Wu L, Jacob R (2007) Seasonal and long-term

Editorial responsibility: Daniel Scott,

Waterloo, Ontario, Canada atmospheric responses to reemerging North Pacific Ocean variability: a combined dynamical and statistical assessment. J Clim 20:955-980

Lorenz EN (1951) Seasonal and irregular variations of the northern hemisphere sea-level pressure profile. J Meteorol 8:52-59

- Marshall J, Kushnir Y, Battisti D, Change P and others (2001) North Atlantic climate variability: phenomenon, impacts and mechanisms. Int J Climatol 21:1863-1898

McCabe GJ, Palecki MA, Betancourt JL (2004) Pacific and Atlantic Ocean influences on multidecadal drought frequency in the United States. Proc Natl Acad Sci USA 101:4136-4141

McKee TB, Doesken NJ, Kleist J (1993) The relationship of drought frequency and duration to time scales. In: Proc 8th Conf Applied Climatology. American Meteorological Society, Boston, p 179-184

Montroy DL, Richman MB, Lamb PJ (1998) Observed nonlinearities of monthly teleconnections between tropical Pacific sea surface temperature anomalies and Central and Eastern North American precipitation. J Clim 11:1812-1835

- Nakamura T, Tachibana Y, Honda M, Yamane S (2006) Influence of the Northern Hemisphere annular mode on ENSO by modulating westerly wind bursts. Geophys Res Lett 33: L07709

NCDC (1994) Time bias corrected divisional temperatureprecipitation-drought index. National Climatic Data Center Documentation for dataset TD-9640. Available from DBMB, NCDC, NOAA, Federal Building, 37 Battery Park Ave., Asheville, NC 28801-2733

New M, Todd M, Hulme M, Jones P (2001) Precipitation measurements and trends in the twentieth century. Int J Climatol 21:1889-1922

> Quadrelli R, Wallace JM (2002) Dependence of the structure of the Northern Hemisphere annular mode on the polarity of ENSO. Geophys Res Lett 29

Randel WJ (2004) Wider connections for El Niño. Nature 431:920-921

Rodó X, Baert E, Comin FA (1997) Variations in seasonal rainfall in southern Europe during present century: relationships with the North Atlantic Oscillation and the El NiñoSouthern Oscillation. Clim Dyn 13:275-284

> Ropelewski CF, Halpert MS (1989) Precipitation patterns associated with the high index phase of the Southern Oscillation. J Clim 2:268-284

- Taguchi M, Hartmann DL (2006) Change in occurrence frequency of stratospheric sudden warmings with ENSO-like SST forcing as simulated WACCM. J Clim 19:324-332

> Thompson DWJ, Lorenz DJ (2004) The signature of the annular modes in the tropical troposphere. J Clim 17:4330-4342

- Thompson DWJ, Wallace JM (1998) The Arctic Oscillation in the wintertime geopotential height and temperature fields. Geophys Res Lett 25:1297-1300

Thompson DWJ, Wallace JM (2000) Annular modes in the extratropical circulation. I: Month-to-month variability. J Clim 13:1000-1016

Wallace JM, Gutzler DS (1981) Teleconnections in the geopotential height field during the northern hemisphere winter. Mon Weather Rev 109:784-812

Wilks DS (1995) Statistical methods in the atmospheric sciences: an introduction. International Geophysics Series, Vol 59. Academic Press, New York

- Yarnal B, Leathers DJ (1988) Relationships between interdecadal and interannual climatic variations and their effect on Pennsylvanian climate. Ann Assoc Am Geogr 78: $624-641$

Zhang Y, Wallace JM, Battisti DS (1997) ENSO-like interdecadal variability: 1900-93. J Clim 10:1004-1020

Submitted: November 19, 2007; Accepted: April 22, 2008

Proofs received from author(s): June 25, 2008 